\title{
Staphylococcus Infection Associated with Arthroplasty
}

\author{
Weisheng Ye, Wei Shang and Yaqiong Yang \\ Tianjin Orthopaedics Hospital \\ P. R. China
}

\section{Introduction}

Prosthetic joints improve the quality of life, but they may fail, necessitating revision or resection arthroplasty. The numbers of primary total hip and total knee arthroplasties have been increasing over the past decade, with nearly 800,000 such procedures performed in the United States in 2006 (Fig.1A)[1], with numbers projected to rise to 572,000 by 2030 and are expected to undergo a continuing rise, especially in light of an aging population[2]. Procedures to replace the shoulder, elbow, wrist, ankle, temporomandibular, metacarpophalangeal and interphalangeal joints are less commonly performed. The growth in the number of prosthetic joint replacement procedures provides new opportunities for infections to take hold.

The classification of the arthroplasty associated infection may distinguishes two major types - septic arthritis and osteomyelitis, which both involve the inflammatory destruction of joint and bone. The incidence of septic arthritis is between 2 and 10 in 100,000 in the general populace but may be as high as $30-70$ per 100,000 in rheumatoid arthritis sufferers or recipients of prosthetic joints [3-5] and is more common in children than adults, and in males rather than females [6]. Haematogenous osteomyelitis most frequently effects children and the elderly [7]. In children, the incidence is typically between 1 in 5000 and 1 in 10,000 [8]. It has been argued that the incidence of haematogenous osteomyelitis is decreasing with an annual fall in childhood cases of 0.185 per 100,000 people recorded in Glasgow, Scotland between 1970 and 1997 [8-10]. Conversely, osteomyelitis resulting from direct infection is reportedly on the increase[10,11]. Local spread of infection from contiguous tissue to bone or direct infection can occur at any age, with foreign body implants a substantial risk factor [7]. Infection, although uncommon, is the most serious complication, occurring in 0.8 to $1.9 \%$ of knee arthroplasties[12-14] and 0.3 to $1.7 \%$ of hip arthroplasties[14-16]. The frequency of infection is increasing as the number of primary arthroplasties increases (Fig. 1B)[17]. These infections are increasingly difficult to treat with the rise in antibiotic-resistant forms.

\section{Risk factors for infection}

Patient-related risk factors for infection include previous revision arthroplasty or previous infection associated with a prosthetic joint at the same site, tobacco abuse, obesity, rheumatoid arthritis, a neoplasm, immunosuppression, and diabetes mellitus. 
Surgical risk factors include simultaneous bilateral arthroplasty, a long operative time $(>2.5$ hours), and allogeneic blood transfusion.

Postoperative risk factors include woundhealing complications (e.g., superficial infection, hematoma, delayed healing, wound necrosis, and dehiscence), atrial fibrillation, myocardial infarction, urinary tract infection, prolonged hospital stay, and S. aureus bacteremia[1215],[18-21].
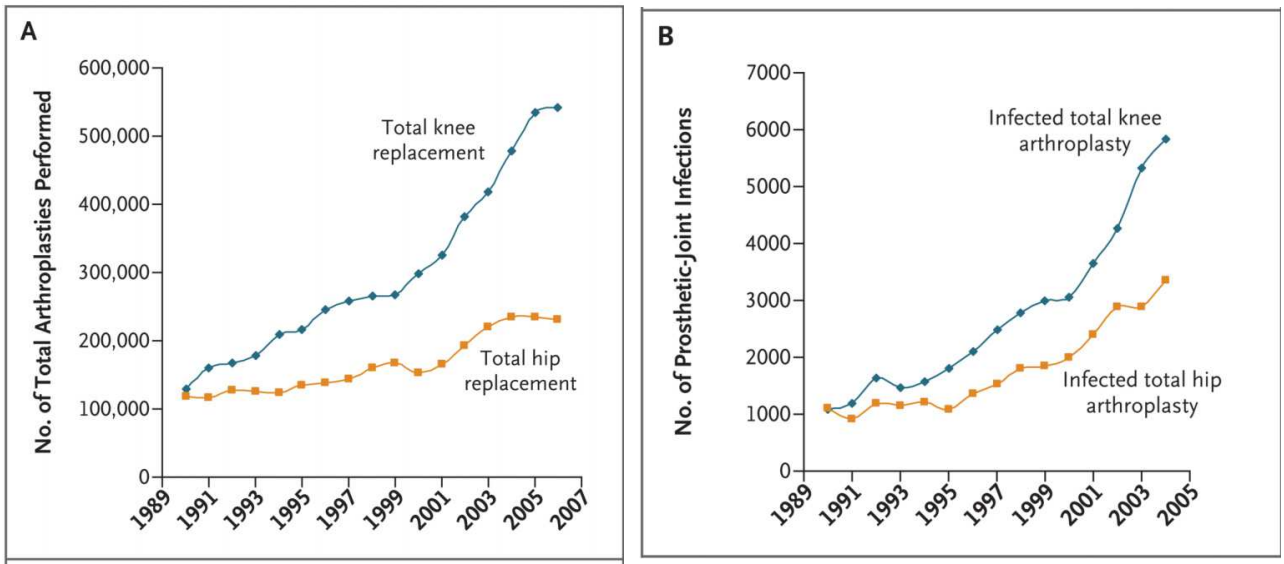

Fig. 1. Total Arthroplasties Performed and Prosthetic Infections, According to Procedure. Panel A shows the number of total arthroplasties performed from 1990 through 2006. Data are from the Centers for Disease Control and Prevention. Panel B shows the number of prosthetic joint infections from 1990 through 2004. Data are from Kurtz et al.

An increased rate of infection occurs in the pre-damaged joint and is also associated with particular predispositions of the patients (Table 1) [22-24]. In articular, a joint prosthesis is a high risk predisposition for an infection. Perioperatively the initial bacterial entry into the joints may occur. On the other hand the implanted foreign material causes in addition to the severe joint disease present an additional reduction in local resistance, which facilitates haematogenous infections. The prosthetic materials are also additional binding sites for various bacteria, and act as a starting point for prosthetic infections. Thus, in addition to the local conditions, the bacterial properties and their specific pathogenity have to be considered for understanding the whole mechanism of infection. Basically, a too late or not

$$
\begin{aligned}
& \text { Preexisting joint defects } \\
& \text { Extraarticular infection } \\
& \text { Diabetes mellitus } \\
& \text { Immunosuppression } \\
& \text { Higher age } \\
& \text { Intraarticular injection or operation } \\
& \text { HLA-B27, for reactive arthritis }
\end{aligned}
$$

Table 1. Predisposing factors 
sufficiently cured joint infection can cause trophic and functional limitations or can even be the starting point of a progressive infection spreading in continuity, lymphogenic or haematogenic. In general, the detection and treatment of acute infectious arthritis is an acute emerging situation, in which a delay may progress to further septic inflammation[23].

\section{Classification of the arthroplasty associated infection}

The arthroplasty associated infection may distinguishes two major types-septic arthritis and osteomyelitis, which both cause serious morbidity and are often difficult to manage.

Septic arthritis is a joint disease typified by bacterial colonisation and rapid articular destruction[6]. Infiltration and growth of bacteria within the synovium results in inflammation with infiltration of leukocytes into the joint fluid [4]. The production of reactive oxygen species and host matrix metalloproteinases (MMPs), lysosomal enzymes and bacterial toxins contribute to the destruction of cartilage. This starts with degradation of host proteoglycans followed by collagen breakdown within hours of infection, and is mediated by polymorphonuclear leukocytes[3-5,24]. The containment of the inflammatory process within the joint results in increasing pressure, which impedes blood and nutrient supply to the joint exacerbating joint damage and facilitating destruction of cartilage and the synovium. Permanent destruction of articular cartilage and subchondral bone can occur rapidly, within just a few days[24].

Osteomyelitis describes a range of infections in which bone is colonized with microorganisms, with associated inflammation and bone destruction. Acute osteomyelitic foci are characterized by pus-forming inflammation at the site of microbial colonisation. Damage to bone matrix and compression and destruction of vasculature is also observed as the infection spreads to surrounding soft tissues, which can further exacerbate bone necrosis[7,10].Sections of dead bone, known as sequestra, can form which may then detach to form separate infectious foci which, due to the lack of vasculature, are protected from immune cells and antibiotics[7,10]. Such areas of dead, infected tissues that are inaccessible to antimicrobials or the immune response can lead to chronic persistence of the infection[10].

The principal routes of these infection involve: (I) haematogenous or lymphogenous seed of the pathogen, (II) contiguous, by contact with a neighboring infected site, (III) or direct, resulting from infiltration of bone, often following inj ury, surgery or implantation of a foreign body, such as joint repalcement[25]. The range of environments experienced by the bacterium differs for each route and hence the virulence factors that are involved in pathology may be different for each route of infection.

Another classification of arthroplasty associated infection distinguishes acute, chronic and reactive forms, which differ in their type of joint infection and their triggering bacteria.

Infection with virulent organisms (e.g., S. aureus and gram-negative bacilli) inoculated at implantation is typically manifested as acute infection in the first 3 months (or, with hematogenous seeding of the implant, at any time) after surgery, whereas infection with less virulent organisms (e.g., coagulase-negative staphylococci and P. acnes) is more often manifested as chronic infection several months (or years) postoperatively. The most common symptom of infection associated with a prosthetic joint is pain. In acute infection, local signs and symptoms (e.g., severe pain, swelling, erythema, and warmth at the infected 
joint) and fever are common. Chronic infection generally has a more subtle presentation, with pain alone, and it is often accompanied by loosening of the prosthesis at the bonecement interface and sometimes by sinus tract formation with discharge.

Reactive arthritis is a postinfectious complication with no need of presence for viable pathogens in the joint. While reactive arthritis often simultaneously affect several joints, the presence of polyarthritic types of non reactive arthritis occur infrequently and then mostly as a result of several bacteriaemic phases.

Among joint infections, the knee is the most frequent localization than others. Infection occurs in 0.8 to $1.9 \%$ of knee arthroplasties[12-14] and 0.3 to $1.7 \%$ of hip arthroplasties[14-16]. However, hip joint infections are aggravated by the fact that they can exist over a long time with only poor symptoms. Basically, there are no differences in the bacterial spectrum among large joints.

\section{Bacteria responsible for arthroplasty associated infection}

A broad range of bacterial species have been isolated in cases of septic arthritis and osteomyelitis[26]. Pathogens cultured from septic joints include S. aureus, Streptococcus pyogenes, Streptococcus pneumoniae, Escherichia coli, Pseudomonas aeruginosa, Serratia marcescens, as well as Salmonella, Neisseria, Aerobacter, and Bacteroides species[4,24]. Staphylococcus and Streptococcus spp., Haemophilusinfluenzae, E. coli, P. aeruginosa, Salmonella and Mycobacterium spp. are all potential causes of osteomyelitis[7,10,27].

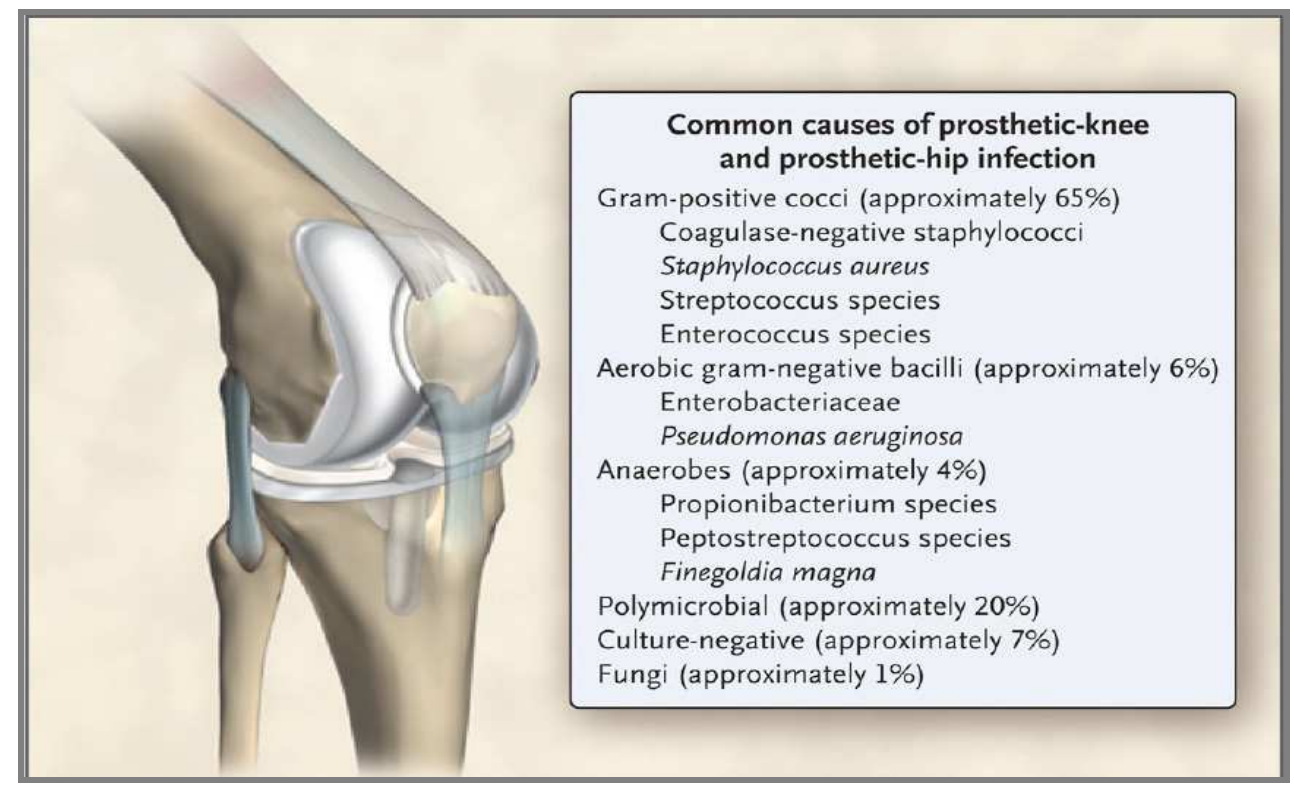

Fig. 2. Causes of Infection Associated with Prosthetic Joints

A small number of often otherwise nonvirulent bacteria contaminate the implant during surgery and persist as a biofilm despite a functional immune system and antimicrobial treatment. Commonly isolated microorganisms are shown. Unusual organisms that can also 
cause infection include (but are not limited to) Actinomyces israelii, Aspergillus fumigatus, Histoplasma capsulatum, Sporothrix schenckii, Mycoplasma hominis, Tropheryma whipplei, and mycobacterium (including tuberculosis), brucella, candida, corynebacterium, granulicatella, and abiotrophia species.

Some bacteria have preferences for certain infection routes and patterns. Infections not related to injuries or medical interventions (e.g. intraarticular puncture, joint replacement) are mostly resulting from often physiologic bacteriaemic periods.

S. aureus is the most commonly identified pathogen both in septic arthritis and osteomyelitis, by a substantial margin, regardless of type or route of infection $[3,7,28]$. Staphylococci (S. aureus and coagulase-negative staphylococcus species) account for more than half of cases of prosthetic-hip and prosthetic-knee infection[29](Fig. 2). Other bacteria

\begin{tabular}{|c|c|}
\hline Bacteria & $\begin{array}{l}\text { Typical mode } \\
\text { of infection }\end{array}$ \\
\hline \multicolumn{2}{|l|}{ Staphylococci } \\
\hline Staphylococcus aureus & NJI, PJI \\
\hline Coagulase negative staphylococci & PJI \\
\hline \multicolumn{2}{|l|}{ Streptococci } \\
\hline beta-hemolytic (e.g. Streptococcus pyogenes) & NJ, RA \\
\hline Streptococcus pneumoniae & NJI \\
\hline \multicolumn{2}{|l|}{ Enterobacteriaceae } \\
\hline Escherichia coli & NJI, PJI \\
\hline Salmonella enterica & \multirow{5}{*}{ NJI, RAs } \\
\hline Shigella spec. & \\
\hline Yersinia spec. & \\
\hline Borrelia burgdorferi sensu lato & \\
\hline Neisseria gonorrhoeae & \\
\hline Pseudomonas aeruginosa & NJI, PJI \\
\hline Bartonella henselae & NJI \\
\hline \multicolumn{2}{|l|}{ Mycobacterium tuberculosis and other mycobacteria } \\
\hline Brucella spp. & \multirow[t]{2}{*}{ NJI } \\
\hline Tropheryma whippelii & \\
\hline \multicolumn{2}{|l|}{ Campylobacter spp. } \\
\hline Chlamydia trachomatis & \multirow{3}{*}{ RAs } \\
\hline Mycoplasma pneumoniae & \\
\hline Ureaplasma urealyticum & \\
\hline
\end{tabular}

Table 2. Bacteria responsible for (hip) joint infections 
and fungi cause the remainder of cases[30,31]. Moreover, Staphylococcus aureus has the dominance in acute septic arthritis, and is particularly common in patients with rheumatoid arthritis[32]while coagulase -negative staphylococci can be found mainly in periprosthetic infections and after diagnostic arthroscopies.

Other gram-positive bacteria as causative agents for hip joint infections are streptococci, especially Streptococcus pyogenes, Enterococcus faecalis and Corynebacteria species. Propionibacterium acnes is a common cause of infection associated with shoulder arthroplasty[33].

A large number of different gram-negative rods act as infectious agents on joints. The group of enterobacteria contains a broad spectrum of pathogens. Salmonella enterica, Shigella species, and Yersinia species are classically described as pathogens for purulent and reactive forms of arthritis. Pseudomonas aeruginosa can be found more often in predisposed patients (e.g. diabetics). In otherwise healthy people it is associated with iatrogenic modes of infection during diagnostic procedures.

Campylobacter species, however, are classic agents of reactive arthritis, as well as the obligate intracellular bacteria Chlamydia trachomatis, Mycoplasma pneumoniae, and Ureaplasma urealyticum. From the spirochaetales only Borrelia burgdorferi sensu lato is relevant. Less commonly identified organisms for joint infections often accompanied with osteitis or osteomyelitis are Brucella species and Mycobacterium tuberculosis.

Up to $20 \%$ of cases are polymicrobial, most commonly involving methicillin -resistant S. aureus (MRSA) or anaerobes, such as Bacteroides fragilis[34]. Approximately $7 \%$ of cases are culture-negative, often in the context of previous antimicrobial therapy[35].

An overview is shown in Table 2[8].

Infection with virulent organisms (e.g., S. aureus and gram-negative bacilli) inoculated at implantation is typically manifested as acute infection in the first 3 months (or, with hematogenous seeding of the implant, at any time) after surgery, whereas infection with less virulent organisms (e.g., coagulase-negative staphylococci and P. acnes) is more often manifested as chronic infection several months (or years) postoperatively.

\section{Interaction of staphylococci with bone}

\subsection{Genomic features of staphylococci associated with bone infections}

A number of studies have attempted to identify an association between the possession of certain virulence genes by Staphylococci and invasive disease. Thus Peacock et al.[36]suggested that the possession of certain combinations of virulence factor genes is associated with invasive disease, and increased severity of infection following examination of a panel of $334 \mathrm{~S}$. aureus isolates by PCR. The isolates comprised those from 179 healthy patients, 94 hospitalacquired isolates and 61 community-acquired isolates. Seven putative virulence genes, including the adhesin genes fnbA and cna, the toxin genes sej, eta and hlg, and icaA, which is involved in biofilm production, were found to be associated with invasive isolates. The association with specific types of invasive infection was not examined and indeed the small number of isolates examined in this study would have precluded such an analysis.

The genes for the fibronectin-binding proteins fnbA and fnbB have been reported to be present in $98 \%$ and $99 \%$ of clinical isolates, respectively, from a range of orthopaedic associated infections, whereas the cna gene, encoding the collagen -binding protein was identified in just $46 \%$ of isolates[37]. Another study by Peacock et al.[38]found the 
prevalence of both fnbA and fnbB genes, as opposed to just one of the two, to be significantly higher in invasive isolates than in 'carriage' strains in a panel of 163 strains, which included septic arthritis and osteomyelitis isolates. Genes encoding Panton-Valentine leukocidin were found to be present in 59 of $89 \mathrm{~S}$. aureus isolates from cases of acute haematogenous osteomyelitis. The presence of pvl genes is associated with an increased risk of severe infection requiring intensive care, bacteremia and more severe systemic inflammation $[39,40]$. However, one of the problems with the above studies is that it is unclear how representative these strain collections are of those isolates carried in other establishments and regions across the world, since strain typing was not reported.

Strain typing studies of S. aureus, using multilocus sequence typing (MLST) and comparative genomic microarray hybridizations have so far failed to identify any specific clonal lineages associated with invasive disease. However, these studies did not use a collection of isolates from specific invasive diseases and therefore do not rule out the possibility that specific lineages or genes are associated with specific types of infection, such as osteomyelitis or septic arthritis.

To date, the only genome comparison study relevant to $S$. aureus bone infections has been done using comparative genome microarray hybridisations of the S. aureus UAMS-1 strain, isolated from an osteomyelitis patient, with a range of genome sequenced strains[41]. These authors found variations in the complement of adhesin, toxin, exoenzyme and regulatory genes. Although it is not possible to draw general conclusions about association with bone infection from characterisation of a single strain, the presence of fnbA, but not fnbB or the bone sialoprotein-binding gene bbp, in UAMS-1 suggest that fnbB and bbp are dispensable for bone infection, at least in certain genetic backgrounds. Thus at this juncture there is a lack of evidence to support or disprove an association between specific $S$. aureus lineages or specific genomic features and the pathogenesis of bone infections.

\subsection{Bone as a target organ}

In terrestrial vertebrates mature bone is made up of dense surface plates of bone, known as the cortices, and within these is a network of bone struts oriented to oppose loading forces, known as trabecular bone. Trabecular bone is typically replaced every 3-4 years, with the denser cortical bone taking over a decade to replace in adults. This process of continual remodelling is required to remove old bone and microfractures to ensure bone integrity and mineral homeostasis. The skeleton is a dynamic organ system, in a state of perpetual turnover which is continually remodelled by the actions of two cell types, osteoblasts and osteoclasts.

Osteoblasts are responsible for the deposition of bone matrix; they are found on bone surfaces and are derived from mesenchymal steoprogenitor cells. These cells secrete osteoid, a mixture of bone matrix proteins primarily made up of type I collagen (over 90\%), proteoglycans such as decorin and biglycan, glycoproteins such as fibronectin, osteonectin and tenascin- $\mathrm{C}$, osteopontin, osteocalcin and bone sialoprotein, oriented along stress lines. Osteoblasts are also thought to facilitate the mineralization of bone matrix, whereby hydroxyapatite, [Ca3(PO4)2]3 $\mathrm{Ca}[\mathrm{OH}] 2$, crystals form, making up around $90 \%$ of bone matrix. It is thought that 'nucleators' are required to instigate mineralisation, and phosphate-containing matrix proteins like bone sialoprotein and osteopontin are likely to play such a role. Osteoblasts also produce tissue nonspecific alkaline phosphatase (TNAP) which cleaves phosphate esters to liberate free inorganic phosphate, which is key to the process of mineralisation[42]. 
Osteoblasts are not terminally differentiated, and some may form osteocytes and become implanted in the bone matrix, eventually ceasing the secretion of osteoid, whilst others undergo apoptosis. Osteocytes are also involved in bone maintenance, detecting stress within the bone through echanosensitive mechanisms located in extensive cellular projections, called canaliculi, that interconnect osteocytes[42]. Osteocytes are thought to respond to mechanical stress by undergoing apoptosis, leading to osteoclast recruitment and differentiation, possibly by alterations in the levels of soluble factors produced by the osteocyte. Candidates include transforming growth factor $\beta$ (TGF- $\beta$ ), which may suppress osteoclastogenesis when produced by healthy osteocytes[43,44].

Osteoclasts, which are multinucleate cells derived from the acrophage-monocyte lineage, perform the opposing action of bone matrix removal. These cells express large quantities of a vacuolar-type $\mathrm{H}+$-ATPase on their cell surface, along with chloride channel $7(\mathrm{ClC}$ 7)enabling localised hydrochloric acid secretion into a closed compartment, known as the resorption lacuna, and subsequent olubilisation of bone mineral. The cell is attached to the bone matrix by a sealing zone membrane to create this compartment, and fusion of acidified vesicles with the plasma membrane contributes further to acid release[45].Following mineral solubilisation, proteolysis of bone matrix proteins is then possible. Cathepsin $\mathrm{K}$ is centrally involved in degradation of bone matrix, it is highly expressed by osteoclasts and digests substrates such as collagen and osteonectin. Evidence from knock-out mouse and selective inhibitor experiments indicates that cathepsin L, and MMPs also play a role in degrading bone matrix[46]. Osteoclasts also secrete acid phosphatases, such as tartrate-resistant acid phosphatase(TRAcP), which is used as an osteoclast marker and is activated by cathepsin $\mathrm{K}$ cleavage. TRAcP is able to generate reactive oxygen species in addition to having phosphatase activity. The exact cellular function of TRAcP in bone resorption is not well understood, but serum TRAcP levels correlate with bone-resorptive activity, and TRAcPdeficient mice exhibit reduced osteoclastic bone resorption and increased bone mineralization.

The balance of activity between these two cell types is crucial to maintaining the proper homeostasis of bone turnover, and any shift in the relative levels of osteoblast and osteoclast activity can result in bone pathology. Infection with a pathogen such as S. aureus is capable of stimulating such a shift, mediated in part by induction of an inflammatory response. There is intimate interaction between the two cell types, with osteoblasts interpreting the majority of extracellular signals and subsequently modulating osteoclast differentiation and function[44].

Interaction between the RANK (receptor activator for nuclear factor $\mathrm{\kappa B}$ ) receptor, expressed by osteoclast precursors, and its cognate ligand, RANKL, expressed by osteoblasts is essential for osteoclastogenesis [44]. RANKL is a homotrimeric protein displayed on the membrane of osteoblasts, although it may be secreted following cleavage by MMPs 7 or 14, or ADAM (a disintegrin and metalloprotease domain). Suppression of MMP 14-mediated secretion enhances osteoclastogenesis[47,48]. The RANK receptor is a homotrimeric transmembrane protein belonging to the tumour necrosis factor (TNF) receptor superfamily. Following binding of RANKL to RANK, TRAF (TNF receptor-associated factor) adaptor proteins are recruited, with binding sites for TRAF2, TRAF5 and TRAF6 all present on RANK. TRAF6 seems to play a central role in RANK mediated osteoclast formation, and mice deficient in TRAF6 are osteopetrotic whereas TRAF2 and TRAF5 are relatively marginal players in osteoclastogenesis. Signalling via RANK, and these adaptor proteins, activates a number of transcription factors, including $\mathrm{NFkB}$ (nuclear factor $\mathrm{kB}$ ), AP- 
1(activator protein 1) and NFATc1 (nuclear factor of activated T-cells, cytoplasmic, calcineurin dependent 1) which drive osteoclast differentiation[44]. Osteoprotegrin (OPG) is an endogenous inhibitor of RANKL signalling, functioning as a decoy receptor that binds to RANKL and prevents its association with RANK.

\subsection{Inflammation in bone infection}

A number of host cytokines play a significant role in the pathogenesis of osteomyelitis, and there is strong evidence that production of these cytokines is induced by staphylococcal infection of bone, and that they directly contribute to bone destruction. In particular, the inflammatory cytokines tumour necrosis factor a (TNFa), interleukin 1 (IL-1) and IL-6 seem to be especially important in bone physiology and pathology. In patients with acute osteomyelitis, plasma levels of TNFa, IL-1 $\beta$ (the secreted form of IL-1) and IL-6 are all elevated. High levels of IL-1 $\beta$, IL-6 and TNFa are also found in the synovial fluid of patients with septic arthritis. Interestingly, specific polymorphisms in the IL-1a and IL-6 genes have recently been found to be associated with an increased risk of osteomyelitis in the Greek population[49]. The most recently identified member of the IL-1 cytokine superfamily is IL33, has been shown to expressed in differentiated osteoblasts and blocks osteoclast formation from bone marrow precursor cells[50].

A number of animal models of $S$. aureus osteomyelitis reveal that bone infection can lead to elevated levels of these cytokines both locally and systemically. Increased levels of IL-1 $\beta$ have been measured in the tibiae of 22-month-old rats experimentally implanted with $S$. aureus infected needles, and the same animals have increased circulating levels of IL-6[51]. In a murine osteomyelitis model, bone levels of IL-1 $\beta$ and IL- 6 are significantly increased in the early post-infection period, with TNFa rising later during the infection. The local source of these cytokines is not fully clear. Production of IL-1 $\beta$ can be induced in human osteoblastlike cell lines by a variety of stimuli, including TNFa. However, infection of primary mouse osteoblasts with S.aureus results in increased transcription, but not increased protein synthesis or secretion of IL-1 $\beta$. TNFa is detectable only at low levels in human osteoblasts derived from mesenchymal stem cells and the osteosarcoma cell line MG63.Infiltrating immune cells may therefore be a more likely source of IL-1 $\beta$ and TNFa in bone in response to infection. IL-6 however, is produced by osteoblasts in response to a variety of signals, including infection with $S$. aureus .

These cytokines have potent effects on the process of bone remodelling, and are strongly implicated in the pathology of osteomyelitis. Cell culture models support the view that IL-1 and TNFa stimulate the proliferation and differentiation of osteoclast progenitors into mature osteoclasts in the presence of osteoblasts. TNFa and IL-1 $\beta$ also stimulate osteoclastmediated bone resorption, a process which may also require the presence of osteoblasts. Similarly, IL-6 increases bone resorption activity and osteoclast number in cultured mouse calvariae, and stimulates osteoclast differentiation in the presence of osteoblasts. In vivo, local administration of IL-1 and TNF antagonists in a non-human primate model of periodontitis results in significant reduction of osteoclast formation and bone destruction. Intravenous administration of TNFa and IL-1 in mice stimulates bone resorption in a dosedependent fashion, and deletion of the murine IL-1R, TNF-R1 and TNF-R2 receptors and of caspase-1 significantly decreases osteoclast number and the area of bone resorption in calvariae following lipopolysaccharide (LPS) injection.

IL-1 $\beta$ and TNFa also inhibit the differentiation of mesenchymal stem cells into osteoblastlike cells, and suppress the accompanying mineralisation and increased expression of 
alkaline phosphatase and procollagen I genes, although only TNFa inhibits osteonectin and osteopontin gene expression[52]. TNFa also decreases production of type I collagen and osteocalcin, and of alkaline phosphatase in a variety of osteoblast cell culture and bone tissue explant models, thereby reducing matrix deposition and mineralisation.

Surface-associated material (SAM) from $S$. aureus stimulates bone resorption and osteoclast formation, and blockade of IL-1 or TNFa signalling completely abolishes this bone resorption activity. Neutralisation of TNFa and IL-6 fully abolishes SAM-stimulated osteoclastogenesis, with antagonism of IL-1 having only a partial effect.

The effect of this SAM on osteoclast formation and stimulation of resorption does not require co-culture with osteoblasts, and does not require RANKL signaling[53]. S.epidermidis surface material can also induce bone resorption, by a mechanism that is strongly dependent on TNFa and, to a lesser extent, IL-1.Induction and release of these cytokines in response to pathogen-associated molecules involves two main classes of pattern recognition receptors (PRRs), the Toll-like receptors (TLRs) and NOD-like receptors (NLRs). The production of TNFa and IL-6 by murine macrophages in response to $S$. aureus cell wall preparations is dependent on TLR2, and TLR2-deficient mice exhibit reduced survival of intravenous $S$. aureus infections compared to wild-type counterparts. Signalling through TLRs, in response to microbial ligands such as LPS, 'primes' the cell for IL-1 $\beta$ production by inducing expression of the inactive, pro-form of the cytokine[54,55].IL-1 $\beta$ is synthesised as a $31-\mathrm{kDa}$ precursor molecule, and is processed to produce a $17-\mathrm{kDa}$ active molecule by caspase- 1 . Caspase- 1 activation, and subsequent processing and release of active IL- $1 \beta$ involves assembly of a multiprotein complex known as the inflammasome. This complex consists of caspase-1, the adaptor protein ASC (apoptosis-associated speck-like protein containing a caspase recruitment domain (CARD)) and one of several NLR proteins, of which four are known to associate with inflammasomes[56].Each NLR responds to different activating signals, and although the exact recognition steps remain to be elucidated, reported stimuli include flagellin, anthrax lethal toxin, and muramyl dipeptide. A broad range of stimuli for NLRP3 (NLR family pyrin domain containing 3) have been reported, including S. aureus. Although NLRP3 and ASC are essential for IL-1 $\beta$ secretion by murine macrophages in response to $S$. aureus, the stimulating signal is as yet unknown, and deletionof the $\alpha-, \beta$ - and $\gamma$-toxins does not perturb production of the cytokine. The inflammasome is involved in cell death in response to bacterial invasion and although invasion of murine osteoblasts by $S$. aureus induces apoptosis, it is not established whether the inflammasome is involved.

Signalling in response to IL-1 and TNF binding of to their respective receptors leads to eventual activation of the NFKB transcription factor and JNK (c-Jun N-terminal kinase) and p38 MAPK(mitogen-activated protein kinase) signaling[57,58]. Studies with knockout mice have shown that at least one of the p50 or p52 NFKB subunits is required for IL-1-induced osteoclast formation and resorptive activity, indicating that much of the osteoclastogenic activity of IL-1 is dependent on NFKB. TNFa binds to two receptors, TNF type I (TNF-R1) and type II (TNF-R2) receptor which differ in their signaling mechanisms although there is substantial signalling crosstalk between the two receptors. Interestingly, the $S$. aureus virulence factor protein $\mathrm{A}$, in addition to possession of immunoglobulin G-binding activity, is able to bind to the TNF-R1 receptor and stimulates downstream signalling and inflammation.

TNFa mediates the osteoclastogenic activity of RANKL. TNFa production by osteoclast progenitors is induced by RANKL and stimulates osteoclast differentiation in an autocrine manner. Signal transduction involves the activation of Janus family (JAK) tyrosine kinases 
and subsequent phosphorylation and activation of STAT (signal transducers and activators of transcription) family transcription factors. IL-6 mediates bone resorption indirectly, and has no effect on isolated osteoclasts and IL-6 induction of osteoclastogenesis is dependent on the expression of the IL-6 receptor by osteoblasts, but not osteoclast progenitors.

It is clear that these cytokines have a prominent role in modulating bone turnover, and perturbation of their levels can have profound effects on this process. Although some mechanistic details are currently lacking, there is strong evidence that $S$. aureus infection of bone initiates local and systemic production of TNFa, IL-1 and IL-6 via host PRRs. Elevated levels of these cytokines then shift the homeostatic balance of bone turnover, increasing osteoclast differentiation and bone resorption and iminishing osteoblast-mediated bone matrix production and mineralisation, thereby driving bone destruction.

\subsection{Staphylococcal invasion of bone cells}

In addition to staphylococcal induction of inflammatory mediators that modulate the actions of osteoblasts and osteoclasts, bacteria of this genus are involved in more direct interactions with bone cells. Invasion and persistence of $S$. aureus in 'non-professional phagocytic' host cells in vitro has been described for many different cell types, including epithelial cells, endothelial cells and keratinocytes[59]. In cell culture systems, S. aureus is able to invade cultured osteoblasts from murine, human and embryonic chick sources, and $S$. epidermidis is also able to invade and grow within cultured osteoblasts. Electron microscopy has demonstrated the presence of bacteria within osteoblasts and osteocytes of embryonic chicks following injection with $S$. aureus, indicating that internalisation by bone cells also occurs in vivo. Intracellular bacteria inside osteoblasts and osteocytes in a patient with recurrent, long-term osteomyelitis of the fibula have been visualised by light and electron microscopy. More recently Stoodley et al. [60] have demonstrated S. aureus biofilms in an infected total joint arthroplasty. Although not reported in this paper the authors also identified S. aureus within host cells (personal communications, Stoodley). Thus the suggestion that internalisation of $S$. aureus by bone cells in vivo provides a protective niche for the bacterium, where it is shielded from immune effector mechanisms and antibiotics, may help to explain persistent cases of osteomyelitis. However, the true importance of intracellular staphylococci in clinical osteomyelitis has yet to be established.

S. aureus requires fibronectin-binding proteins (FnBPs) expressed on the surface of the bacterium to enable uptake by osteoblasts, and many other cell types. These proteins belong to a group of adhesions known as MSCRAMMs (microbial surface components recognising adhesive matrix molecules), which bind a range of extracellular matrix proteins including fibronectin, fibrinogen, collagen, elastin and bone sialoprotein. Mutants deficient in the two FnBPs, FnBPA and FnBPB invade host cells very poorly. Invasion is dependent on fibronectin binding by these proteins, and on the host cell integrin a5 $\beta 1$ receptor. S. aureus binds to fibronectin via FnBPs displayed on the bacterial surface, and fibronectin serves as a bridging molecule to the integrin a5 $\beta 1$ which acts as a "phagocytic"receptor. Alternative uptake mechanisms do exist in certain cell types, however, as $S$. aureus is still able to invade primary keratinocytes in the absence of FnBPs and uptake is not inhibited by blockade of integrin a $5 \beta 1$ binding to fibronectin. The mechanism of invasion also differs between $S$. aureus and $S$. epidermidis and the latter does not gain entry via the fibronectin-integrin a $5 \beta 1$ mechanism[61].

The level of expression of the alternative sigma factor, $\sigma \mathrm{B}$, affects $f n b A$ expression and the fibronectin binding ability of $S$. aureus strains and correlates with the level of internalization 
of bacteria by osteoblasts suggesting that $\sigma$ B-mediated up-regulation of FnBP expression may facilitate invasion[62].

Integrin $\alpha 5 \beta 1$-mediated uptake of $S$. aureus requires remodelling of the actin cytoskeleton. The integrin-linked kinase, ILK, provides a link between $\alpha 5 \beta 1$ and the cytoskeleton, and interacts with the cytoplasmic domains of $\beta$ integrins and is subsequently activated. ILK activity is required for internalisation of $S$. aureus by epithelial cells. Recruitment of focal adhesion proteins, including the adaptor protein paxillin and the focal adhesion kinase, FAK, follows. Upon infection of HEK293T cells with S. aureus there is also recruitment of focal adhesion proteins, such as tensin, zyxin and vinculin to the site of bacterial attachment. FAK is recruited and tyrosine phosphorylated, and FAK-deficient cells are able to internalise $S$. aureus much less efficiently. Phosphorylation of downstream substrates of FAK, including cortactin, which is involved in actin cytoskeletal organisation, occurs during invasion, and interference with cortactin also reduces internalisation. So, signalling downstream of the integrin $\alpha 5 \beta 1$ receptor, involving ILK and FAK, is important for $S$. aureus invasion, at least in certain cell types.

Physical contact between $S$. aureus and osteoblasts induces host cell expression of tumour necrosis factor apoptosis inducing ligand (TRAIL). TRAIL is a member of the TNF cytokine family, and binds to two death domain -containing receptors, TRAIL receptors 1 and 2, which once activated recruit the FADD (Fas-associated protein with death domain) adaptor protein which in turn activates caspases 8 and -10 and commits the cell to an apoptotic pathway[63]. TRAIL produced by $S$. aureus-infected osteoblast induces caspase- 8 activation and apoptosis in cultured osteoblasts. Uninfected osteoblasts cultured alongside infected cells also express TRAIL[64]. TRAIL can induce apoptosis in human osteoclasts via TRAIL receptor 2, and also inhibits osteoclast differentiation. It is therefore possible that apoptosis of bone cells infected with $S$. aureus, and potentially of neighbouring uninfected cells may contribute to bone loss in osteomyelitis .

Growing experimental support indicates that staphylococcal invasion of osteoblasts, most likely via the FnBP-fibronectin-integrin a5 $\beta 1$ bridging mechanism in the case of $S$. aureus, may play a role in the pathogenesis of bone infections. This intracellular location may provide a protected environment for bacteria, aiding prolonged persistence by enabling evasion of antimicrobials and host immune mechanisms and possibly contributing to bone damage by inducing apoptosis of infected cells.

\subsection{Staphylococcal virulence determinants}

A number of animal models of bone implant infection, osteomyelitis and septic arthritis have been developed which have enabled the role of specific virulence factors in infections to be determined. As mentioned at the outset there are a number of routes of bone infection, i.e. haematogenous, contiguous and direct infection of bone, and models have been developed to mimic each of these routes of infection. This is important since the range of environments experienced by the bacterium differs for each route and hence the virulence factors that are involved in pathology may be different for each route of infection. The septic arthritis model developed by Tarkowski and colleagues in conjunction with defined isogenic mutants deficient in one or more virulence determinants, or with neutralising antibodies to virulence factors has proven to be particularly useful in elucidating the role of specific virulence determinants and host factors in bone infections. This model has shown that there is a plethora of virulence determinants involved in S. aureus septic arthritis. some of which are also involved in osteomyelitis. However, there is some controversy in this area 
because whilst the murine septic arthritis model is well established and standardised a number of different models have been developed for osteomyelitis and the relevance of specific virulence factors to bone implant infections or osteomyelitis appears to be dependent on the particular model used. For example the collagen adhesin Cna has been shown to contribute to osteomyelitis by some workers but not by others and has been reported not to be important in orthopaedic device infections. The role of FnBPs has not been directly assessed in a model of osteomyelitis, but comparison of $S$. aureus strains with and without fibronectin-binding activity in a mouse osteomyelitis model suggests that fibronectin-binding strains may give rise to more severe bone infections. In the septic arthritis model, $S$. aureus fnbA fnbB mutants show no reduction in severity of arthritis, in contrast with $c l f A$ clfB mutants lacking the fibrinogen-binding clumping factors. However, the presence of the $f n b$ genes results in greater weight loss and mortality, as well as higher serum levels of IL-6, indicating a role for FnBPs in the systemic inflammatory response.

One area of research that has received surprisingly little attention is that of the direct action of virulence factors on bone and bone cells. Work in our own laboratory has shown that S.aureus and S. epidermidis produce surface-associated proteins that can stimulate bone breakdown in an in vitro assay. These surface-associated proteins and capsular material appear to promote the formation and activation of the boneresorbing osteoclast. Interestingly, a proportion of the population have antibodies that can block the action of the $S$. aureus proteins and prevent bonebreakdown. The identity of the protein(s) in these mixtures which cause bone destruction has not been elucidated.

\subsection{Small colony variants}

Variant forms of $S$. aureus, known as small colony variants (SCVs), are associated with infections of bone and joint that may be particularly persistent, recurrent and refractory to antibiotic treatment[65]. These bacteria are mutant forms of Staphylococcus that may have an adaptive advantage enabling persistent bone colonisation.

SCV forms of coagulase-negative staphylococci, including S. epidermidis, S. lugdunensis and S. capitis have also been isolated from a range of infections. The SCV phenotype is characterised by slow growth, with colonies around 10-fold smaller than wild-type forms, often with decreased pigmentation, increased aminoglycoside resistance and some reports of reduced haemolytic activity[66]. The nature of these phenotypes can cause difficulty in detection and identification of the bacteria, and may contribute to an underestimation of the clinical prevalence of SCVs [67]. These phenotypes usually result from auxotrophy for hemin, menadione or thymidine and can be reversed by supplementation with these molecules. Mutations in the hemB and menD genes produce hemin and menadione auxotrophic strains with typical SCV phenotypes, and give rise to disruption of electron transport which is the basis of the growth deficiency, increased minoglycoside resistance and other phenotypes. SCVs can be selected for with gentamicin in vitro, and there is evidence that antibiotic therapy, in particular use of gentamicin beads, which are used in addition to debridement and systemic antibiotic therapy for osteomyelitis may select for SCVs in clinical situations. In a cohort of fourteen patients with confirmed $S$. aureus osteomyelitis, SCVs were isolated only from those four that had received gentamicin bead therapy, with the remaining ten patients harbouring normal $S$. aureus strains. Of the four SCVs, three were auxotrophic for hemin, and one for menadione. Only the patients harbouring SCVs had recurrent infections, although only patients whose gentamicin bead 
therapy had failed were included in the study. SCVs have also been isolated from cases of infection of hip prostheses, and intracellular bacteria within host fibroblasts were identified in one of the five instances.

Clinically isolated SCVs with hemin auxotrophy, and defined hemB mutants, show enhanced intracellular persistence in a range of human cell types. The basis of this persistence is not established but may involve a number of possible mechanisms. S. aureus hemB mutants exhibit enhanced binding to fibrinogen and fibronectin, and transcribe and display more ClfA and FnBP on their surface, which may increase attachment and uptake by host cells. Transcriptional profiling of clinical and defined mutant SCVs reveals increased transcription of genes regulated by $\sigma \mathrm{B}$, including adhesin genes, and down-regulation of exoprotein and toxin genes. The effect of increased $\sigma \mathrm{B}$ activity on MSCRAMM expression has been shown to correlate well with osteoblast invasion, adding weight to the argument that $\sigma$ B-mediated upregulation of adhesins increases host cell invasion, at least in vitro, and that increased invasion by SCVs may be partially dependent on this mechanism. It has been argued that reduced production of toxins, particularly haemolysins, by SCVs also contributes to intracellular persistence by reducing the cytotoxic effect on host cells.

In a murine septic arthritis model, a defined stable hemB mutant, exhibiting the SCV phenotype, elicited more frequent and severe arthritis than the parental strain despite a reduced bacterial load in the kidney and joints. It has been argued that SCVs are therefore more virulent on a'per organism' basis and that enhanced protease production by hemB mutants may partially explain this. It may be that in clinical infections relatively small numbers of SCVs with enhanced virulence survive within tissues, possibly intracellularly, for extended periods and cause persistent infections. Clinically isolated SCVs are able to revert to the parent phenotype, although to what extent this may play a role in infections, and whether $S$. aureus may 'switch' between states in different in vivo situations is currently unclear.

\section{Diagnostic approach}

It is important to accurately diagnose prosthetic-joint-associated infection because its management differs from that of other causes of arthroplasty failure. Although there is no universally accepted definition of this type of infection, the criteria listed in Table 3 have been applied in a number of studies.

The presence of at least one of the following findings:

- Acute inflammation detected on histopathological examination of periprosthetic tissue

- Sinus tract communicating with the prosthesis

- Gross purulence in the joint space

- Isolation of the same microorganism from two or more cultures of joint aspirates or intraoperative periprosthetic-tissue specimens, isolation of the organism in substantial amounts (e.g., $\geq 20 \mathrm{CFU}$ per 10 $\mathrm{ml}$ from the implant in a total volume of $400 \mathrm{ml}$ of sonicate fluid), or both

Table 3. Criteria for the Diagnosis of a Prosthetic-Joint Infection. 
Establishing the presence of acute infection or, in the presence of a draining sinus, chronic infection, is uncomplicated. In these situations, testing may be limited to that needed to establish the microbiologic diagnosis. Chronic infection manifested as localized joint pain alone poses more diagnostic difficulty, warranting additional testing. The criteria for interpreting laboratory and imaging findings in patients with a prosthetic joint are distinct from those applied in patients with a native joint. In addition to establishing the diagnosis, the identification of the involved organism or organisms and their antimicrobial susceptibility (i.e., on the basis of cultures of synovial fluid, periprosthetic tissue, the implant, or a combination of such cultures) is important in order to guide antimicrobial therapy.

C-Reactive Protein-In the absence of underlying inflammatory conditions, CRP measurement is the most useful preoperative blood test for detecting infection associated with a prosthetic joint. CRP testing has a sensitivity of 73 to $91 \%$ and a specificity of 81 to $86 \%$ for the diagnosis of prosthetic-knee infection with the use of a cutoff point of $13.5 \mathrm{mg}$ per liter or more[68,69]. It has a sensitivity of $95 \%$ and a specificity of $62 \%$ for the diagnosis of prosthetichip infection with the use of a cutoff point of more than $5 \mathrm{mg}$ per liter[70]. Although the CRP level and erythrocyte sedimentation rate are elevated after uncomplicated arthroplasty, the CRP level returns to the preoperative level within 2 months, whereas the erythrocyte edimentation rate may remain elevated for several months. A normal CRP level generally indicates an absence of infection, although false negative results may occur in patients who have been treated with antimicrobial agents or who have infection that is caused by low-virulenceorganisms such as P. acnes. Elevations in the peripheral -blood leukocyte count and levels of procalcitonin have low sensitivity for detecting infection.

Imaging-Plain radiography has low sensitivity and low specificity for detecting infection associated with a prosthetic joint[71]. Periprosthetic radiolucency, osteolysis, migration, or all of these features may be present on radiographs in patients with either infection or aseptic loosening of the prosthesis. Diagnostic studies with the use of computed tomography (CT) or magnetic resonance imaging (MRI) are hampered by artifacts produced by prostheses, although implants that are not ferromagnetic (i.e., titanium or tantalum) are associated with minimal MRI artifacts, and MRI scans of such implants provide good resolution for detecting soft-tissue abnormalities. Bone scans obtained after the administration of technetium-99m -labeled methylene diphosphonate are sensitive for detecting failed implants but nonspecific for detecting infection, and they may remain abnormal for more than a year after implantation.

Some studies suggest that combined bone and gallium- 67 scans are more specific than bone scans alone. However, labeled-leukocyte imaging (e.g., leukocytes labeled with indium-111) combined with bone marrow imaging with the use of technetium $-99 \mathrm{~m}$-labeled sulfur colloid is more accurate than bone imaging alone, combined bone and gallium- 67 imaging, or labeledleukocyte and bone imaging when compared head to head, and it is considered the imaging test of choice when imaging is required[71]. 18F-fluorodeoxyglucose positronemission tomography (PET) has a sensitivity of $82 \%$ and a specificity of $87 \%$ for the detection of prosthetic-knee or prosthetic-hip infection, on the basis of pooled data from several studies, but it is not widely available[72]. Newer imaging strategies such as scintigraphy with antigranulocyte monoclonal antibodies and hybrid imaging (e.g., combined PET and CT) (see Fig. 3)are under investigation. 

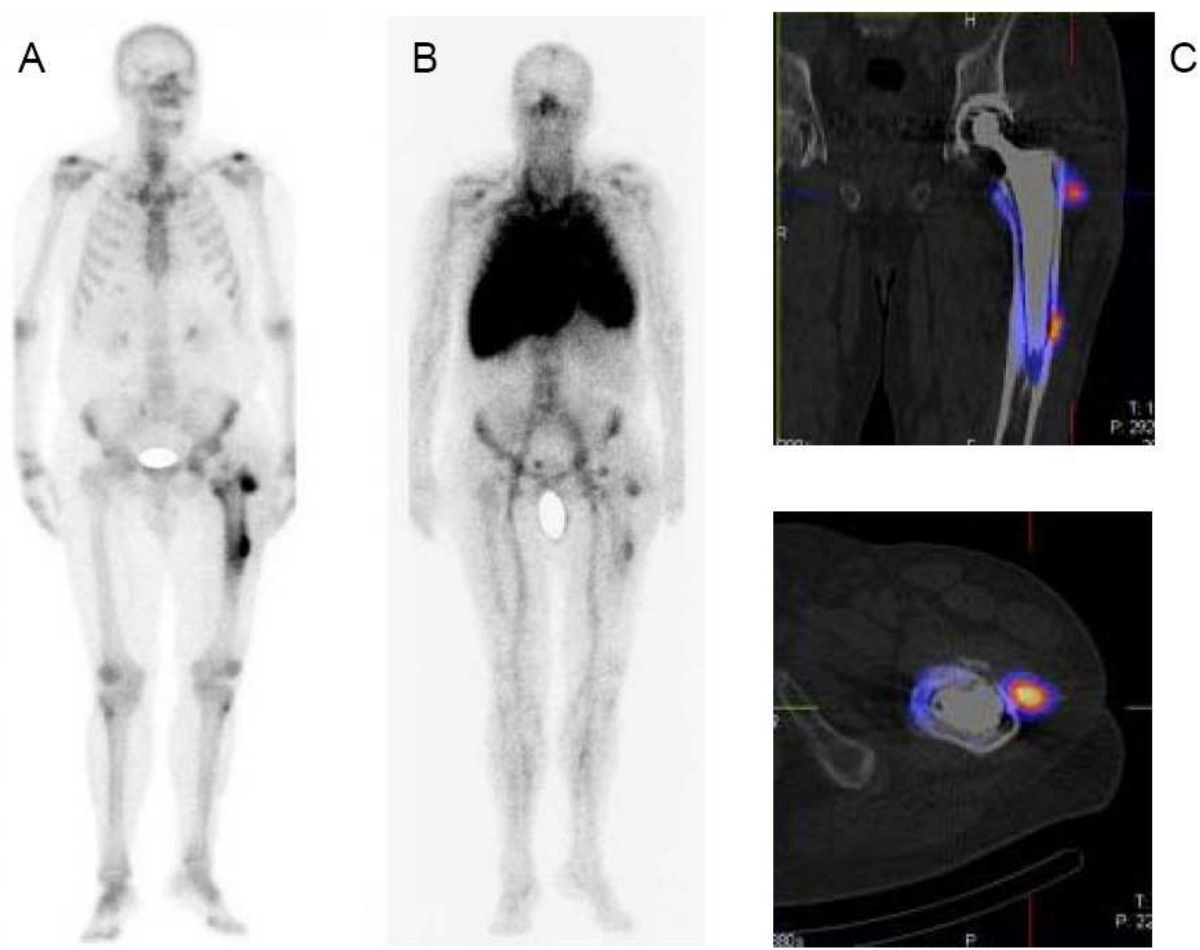

Fig. 3. Bone Scan, Labeled-Leukocyte Scan and Positron Emission Tomography/Computed Tomography Scan from a Patient with Prosthetic Joint Infection.

In Panel A, an anterior bone scan obtained after the administration of technetium-99mlabeled methylene diphosphonate shows diffusely increased activity around the femoral component of a left hip replacement, with foci of increased activity at the tip of the femoral component and around the tibia. In Panel B, a labeled leukocyte scan obtained after the administration of indium-111-labeled leukocytes shows accumulation of labeled leukocytes that is spatially congruent with the bone scan image shown in Panel A. In Panel C, 18Ffluoro-2-deoxyglucose positron emission tomography/computed tomography coronal and sagittal images show increased activity around the bone-prosthesis interface. Staphylococcus epidermidis and Finegoldia magna were isolated from the periprosthetic tissue. (Images courtesy of Carmen Vigil, M.D., and Jose Angel Richter, M.D., Department of Nuclear Medicine, University Hospital of Navarre, Pamplona, Spain.)

Synovial-Fluid Studies-If there is uncertainty about the diagnosis, the most useful preoperative diagnostic test is aspiration of joint synovial fluid for a total and differential cell count and culture. Aspiration should not be performed through overlying cellulitis. Hip aspiration may require imaging guidance. A synovial-fluid leukocyte count of more than $1.7 \times 103$ per cubic millimeter or a differential count with more than $65 \%$ neutrophils is consistent with prosthetic-knee infection. A synovial-fluid leukocyte count of more than $4.2 \times 103$ per cubic millimeter or more than $80 \%$ neutrophils is consistent with prosthetic-hip infection[73]. The leukocyte count cutoffs are dramatically lower than those used to 
diagnose native-joint infection. Synovial-fluid culture has a sensitivity of 56 to $75 \%$ and a specificity of 95 to $100 \%$, and to achieve optimal sensitivity and specificity, it should be performed by means of inoculation into a blood-culture bottle. If an organism of questionable clinical significance is isolated, repeat synovial-fluid aspiration for culture should be considered. Previous antimicrobial treatment reduces the sensitivity.

Histopathological Examination of Periprosthetic Tissue-In patients in whom the diagnosis of prosthetic-joint-associated infection has not been established preoperatively, an intraoperative frozen section may be obtained to look for evidence of acute inflammation. In studies that used a polymorphonuclear-cell count ranging from more than 5 to 10 or more cells per high-power field as a positive test, sensitivity for infection ranged from 50 to $93 \%$ and specificity ranged from 77 to $100 \%$; the rate of interobserver agreement was $86 \%$.

Intraoperative Microbiologic Testing-Identification of the pathogen or pathogens is critical for choosing the antimicrobial regimen; if microbiologic testing has not been done preoperatively, specimens should be collected for microbiologic study at the time of surgery. Antimicrobial therapy should be discontinued at least 2 weeks before surgery, and perioperative antimicrobial coverage should be deferred until culture specimens have been collected. Cultures of sinus tract exudates should be avoided; these are often positive because of microbial skin colonization and correlate poorly with cultures of surgical specimens.

If periprosthetic tissue is obtained, collection of multiple periprosthetic-tissue specimens for aerobic and anaerobic bacterial culture is imperative because of the poor sensitivity of a single culture and to distinguish contaminants from pathogens. A study that used mathematical modeling to estimate yield based on the number of cultures concluded that to maximize accuracy, five or six specimens should be submitted for culture, and two or three culturepositive samples would be considered to be diagnostic.

Periprosthetic-tissue cultures may be falsely negative because of previous antimicrobial therapy, leaching of antimicrobial agents from antimicrobial -impregnated cement, biofilm growth on the surface of the prosthesis (but not in the surrounding tissue), a low number of organisms in tissue, an inappropriate culture medium, an inadequate culture incubation time, or a prolonged time to transport the specimen to the laboratory. Because of poor sensitivity, neither intraoperative swab cultures nor Gram's staining of the periprosthetic tissue is recommended. Fungal cultures, mycobacterial cultures, or both may be considered (e.g., if bacterial cultures are negative in a patient with apparent infection), but they are not routinely recommended.

Microorganisms form a biofilm on the prosthesis; therefore, if the prosthesis is removed, obtaining a sample from its surface is useful for microbiologic diagnosis. The implant is removed and transported to the laboratory in a sterile jar. After the addition of Ringer's solution, the container is vortexed and sonicated (frequency, $40 \mathrm{kHz}$; power density, $0.22 \mathrm{~W}$ per square centimeter) for 5 minutes in a bath sonicator, and the resultant fluid is cultured. This technique is more sensitive than and as specific as multiple periprosthetic-tissue cultures for diagnosing infection of a prosthetic hip, knee, or shoulder, provided that an appropriate cutoff for significant results is applied. This technique is particularly helpful in patients who have received previous antimicrobial therapy. In a study involving patients receiving antimicrobial agents within 2 weeks before surgery, the sensitivity of periprosthetic-tissue culture was $45 \%$, whereas the sensitivity of sonicate-fluid culture was $75 \%(\mathrm{P}<0.001)$. Sonication in bags is not recommended because of the potential for contamination. 


\subsection{Treatment}

The goal of treatment is to cure the infection, prevent its recurrence, and ensure a pain-free, functional joint. This goal can best be achieved by a multidisciplinary team consisting of an orthopedic surgeon, an infectious-disease specialist, and a clinical microbiologist. On the basis of clinical experience, the use of antimicrobial agents alone, without surgical intervention, ultimately fails in most cases. Careful surgical débridement is critical. A general approach to surgical management is outlined in Figure 4; different centers and surgeons may use slightly different strategies. Chronic infections require resection arthroplasty either as a onstage exchange (i.e., removal of the infected prosthesis and reimplantation of a new prosthesis during the same surgical procedure) or a two-stage exchange (i.e., removal of the infected prosthesis and administration of systemic antimicrobial agents with subsequent implantation of a new prosthesis, usually between 6 weeks and 3 months after the first stage). Case series have suggested improved outcomes with a one-stage exchange when polymethylmethacrylate impregnated with one or more antimicrobial agents is used. A spacer impregnated with one or more antimicrobial agents may be used to maintain the leg at its correct length and to control infection during the prosthesis-free interval of a two-stage exchange. In a randomized trial involving patients with infection associated with hip arthroplasty, the use of a vancomycinloaded spacer (as compared with no spacer) resulted in a lower rate of recurrent infection (11\% vs. $33 \%, \mathrm{P}=0.002)[74]$.

Patients who have had symptoms of infection for fewer than 3 weeks, who present with infection within 3 months after implantation or who have hematogenous infection, and who have a well-fixed, functioning prosthesis, without a sinus tract, and with an appropriate microbiologic diagnosis (Fig. 4) may be candidates for débridement and retention of the prosthesis. The addition of rifampin is recommended in cases of rifampin-susceptible staphylococcal infection. In a small, randomized trial comparing different antibiotic regimens in patients with staphylococcal infection of prosthetic knees or hips or osteosynthetic implants, salvage of the implant was successful in all 12 patients treated for 3 to 6 months with rifampin and ciprofloxacin, as compared with successful salvage in 7 of 12 patients treated with ciprofloxacin alone for 3 to 6 months $(\mathrm{P}=0.02)$.

When unacceptable joint function is anticipated after surgery or the infection has been refractory to multiple surgical attempts at cure, resection arthroplasty with creation of a pseudarthrosis for hips (Girdlestone resection) or arthrodesis for knees may be considered. If the patient is not a candidate for surgery, antimicrobial suppression may be attempted; this approach is unlikely to cure infection, so the use of antimicrobial agents is often continued indefinitely.

In brief, information about antimicrobial susceptibility should be used to confirm the activity of any antimicrobial agent used for therapy. Data from randomized trials on the optimal duration of treatment are lacking. The therapeutic approach has to be selected in accordance with the mode of infection (NJI, PJI, RA), the expected or found pathogens, and their resistance. It should be remembered that the slowed growth of bacteria in a biofilm on surfaces of joint prosthesis may additionally reinforces antibiotic resistance. Responsible for such an increase against antibacterial substances are changes in cell wall synthesis, which limits the effect of beta-lactam antibiotics and glycopeptides, and the occurrence of bacterial variants with modifications of other metabolic activities, with implications for the action of quinolones, aminoglycosides, and tetracyclines. In principle, the spectrum of available antibiotics is limited by the specific pharmacokinetic requirements in the treatment of joint infections. This applies particularly to chronic infections and prosthesis infections. 


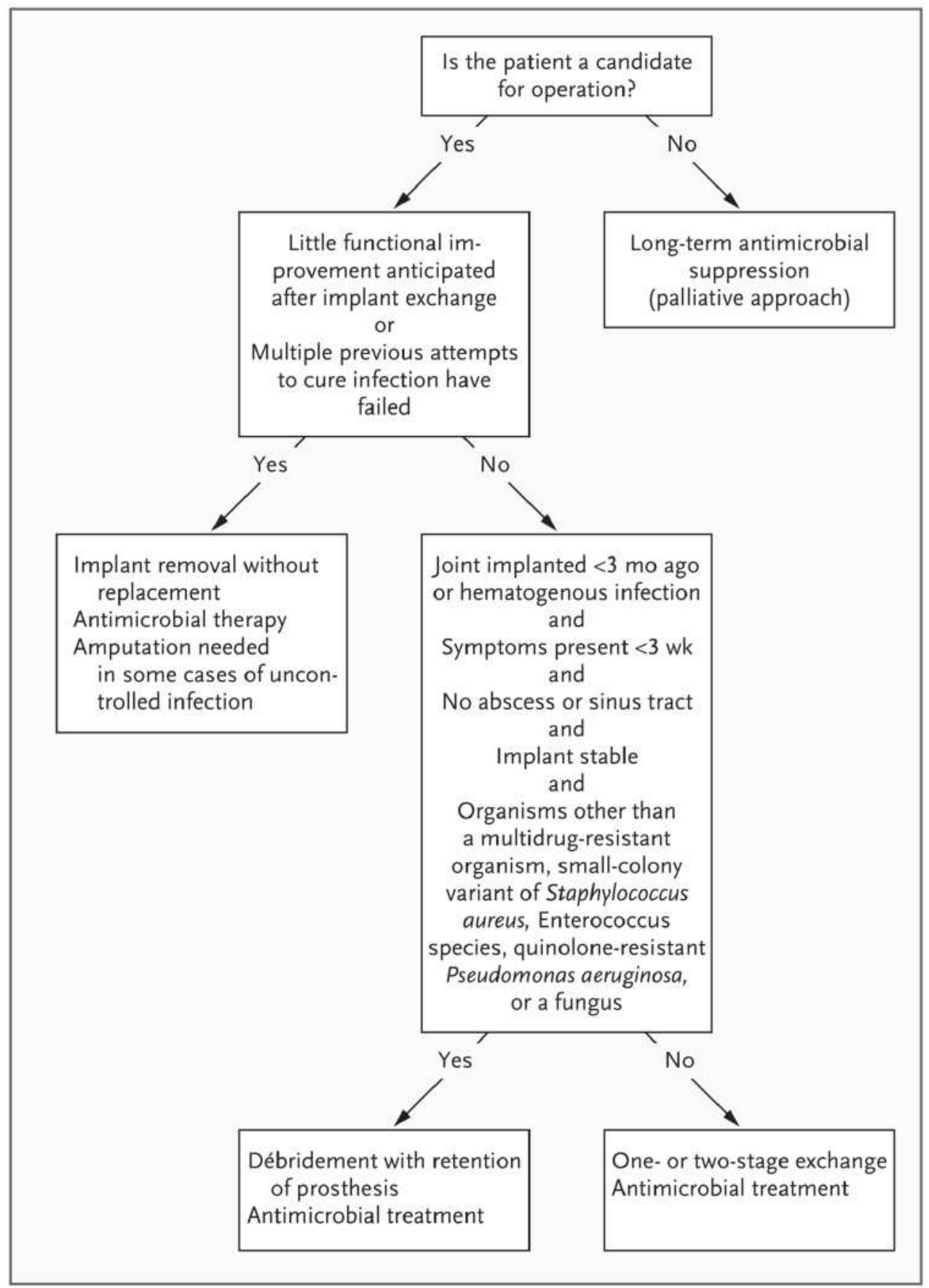

Fig. 4. Algorithm for the Treatment of Infection Associated with a Prosthetic joint 


\begin{tabular}{|c|c|c|}
\hline \multirow{2}{*}{ Organism } & \multicolumn{2}{|c|}{ Antibiotics } \\
\hline & Native joint infection & Prosthetic joint infection \\
\hline $\begin{array}{l}\text { Methicillin resistant } \\
\text { Staphylococcus aureus }\end{array}$ & \multirow{2}{*}{$\begin{array}{l}\text { (I) First choice: } \\
\text { Vancomycin } 2 \times 1 \mathrm{~g} / \mathrm{d} \\
\text { Linezolid } 2 \times 600 \mathrm{mg} / \mathrm{d} \\
\text { (II) Alternatives: } \\
\text { Cotrimoxazol, Doxycyclin, } \\
\text { Clindamycin, Rifampicin (always in combination) }\end{array}$} & \multirow{2}{*}{$\begin{array}{l}\text { (1) First choice (in combination with } \\
\text { Rifampicin } 600-900 \mathrm{mg} \text { ): } \\
\text { Vancomycin } 2 \times 1 \mathrm{~g} / \mathrm{d} \\
\text { Teicoplanin } 800 \mathrm{mg} / \mathrm{d} \text { for the first } 1-4 \text { days, } \\
\text { than } 800 \mathrm{mg} \text { every } 2 \text { days } \\
\text { Fluoroquinolone }(\mathrm{e} . \mathrm{g} \text {. Ciprofloxacin } 2 \times 500-750 \mathrm{mg} / \mathrm{d} \text { ) } \\
\text { Fusidinsäure } 3 \times 500 \mathrm{mg} / \mathrm{d} \\
\text { (II) Alternatives: } \\
\text { Linezolid, Quinupristin/Dalfopristin }\end{array}$} \\
\hline $\begin{array}{l}\text { Methicillin resistant } \\
\text { coagulase negative } \\
\text { staphylococci }\end{array}$ & & \\
\hline $\begin{array}{l}\text { Methicillin sensitive } \\
\text { Staphylococcus aureus }\end{array}$ & \multirow{2}{*}{$\begin{array}{l}\text { (I) First choice: } \\
\text { beta-lactamase stable penicillin (e.g. } \\
\text { Flucloxacillin } 4 \times 2-3 \mathrm{~g} / \mathrm{d} \text {, } \\
\text { Nafcillin } 4 \times 2 \mathrm{~g} / \mathrm{d} \text { ) } \\
\text { Clindamycin } 3 \times 600-900 \mathrm{mg} / \mathrm{d} \\
\text { (II) Alternatives: } \\
\text { Cefazolin, Vancomycin }\end{array}$} & \multirow{2}{*}{$\begin{array}{l}\text { (I) First choice (in combination with } \\
\text { Rifampicin } 600-900 \mathrm{mg} \text { ): } \\
\text { Flucloxacillin } 4 \times 2-3 \mathrm{~g} / \mathrm{d} \\
\text { Fluoroquinolone }(\mathrm{e} . \mathrm{g} \text {. Ciprofloxacin } 2 \times 500-750 \mathrm{mg} / \mathrm{d} \text { ) } \\
\text { (II) Alternatives (in combination with Rifampicin): } \\
\text { Cefazolin, Vancomycin }\end{array}$} \\
\hline $\begin{array}{l}\text { Methicillin sensitive } \\
\text { coagulase negative } \\
\text { staphylococci }\end{array}$ & & \\
\hline beta-hemolytic Streptococci & $\begin{array}{l}\text { (I) First choice: } \\
\text { Penicillin G } 6 \times 2 \text { million units/d } \\
\text { Ampicillin } 3 \times 2 \mathrm{~g} / \mathrm{d} \\
\text { (II) Alternatives: } \\
\text { Clindamycin, Cefazolin }\end{array}$ & $\begin{array}{l}\text { (I) First choice } \\
\text { Penicillin } \mathrm{G} 6 \times 4-5 \text { million units/d } \\
\text { Ampicillin } 3 \times 4 \mathrm{~g} / \mathrm{d} \\
\text { (II) Alternatives: } \\
\text { Vancomycin, Ceftriaxon }\end{array}$ \\
\hline Enterococcus spec. & $\begin{array}{l}\text { (I) First choice: } \\
\text { Ampicillin } 3 \times 2 \mathrm{~g} / \mathrm{d} \\
\text { Vancomycin } 2 \times 1 \mathrm{~g} / \mathrm{d} \\
\text { (II) Alternatives: } \\
\text { Linezolid }\end{array}$ & $\begin{array}{l}\text { (I) First choice } \\
\text { Ampicillin } 3 \times 4 \mathrm{~g} / \mathrm{d} \\
\text { Vancomycin } 2 \times 1 \mathrm{~g} / \mathrm{d} \\
\text { Teicoplanin } 800 \mathrm{mg} / \mathrm{d} \text { for the first } 1-4 \text { days, } \\
\text { than } 800 \mathrm{mg} \text { every } 2 \text { days } \\
\text { (II) Alternatives: } \\
\text { Linezolid }\end{array}$ \\
\hline Escherichia coll & $\begin{array}{l}\text { (I) First choice: } \\
\text { Ampicillin/Sulbactam } 4 \times 3 \mathrm{~g} / \mathrm{d} \\
\text { (II) Alternatives: } \\
\text { Cefazolin, Fluoroquinolone (e.g. Ciprofloxacin), } \\
\text { Gentamicin, Cotrimoxazole }\end{array}$ & \multirow{3}{*}{$\begin{array}{l}\text { (I) First choice: } \\
\text { Ciprofloxacin } 2 \times 500-750 \mathrm{mg} / \mathrm{d} \\
\text { Cefotaxime } 3-4 \times 2 \mathrm{~g} / \mathrm{d} \\
\text { Piperacillin } / \text { Tazobactam } 3 \times 4 \mathrm{~g} / 0,5 \mathrm{~g} / \mathrm{d} \\
\text { (II) Alternatives: } \\
\text { Imipenem, Meropenem }\end{array}$} \\
\hline Proteus mirabilis & $\begin{array}{l}\text { (I) First choice: } \\
\text { Ampicillin } 3 \times 2 \mathrm{~g} / \mathrm{d} \\
\text { Fluoroquinolone (e.g. Ciprofloxacin } 2 \times 500-750 \mathrm{mg} / \mathrm{d} \text { ) } \\
\text { (II) Alternatives: } \\
\text { Cefazolin, Cotrimoxazole, Gentamicin }\end{array}$ & \\
\hline $\begin{array}{l}\text { Proteus vulgaris } \\
\text { Proteus rettgeri } \\
\text { Morganella morganii }\end{array}$ & $\begin{array}{l}\text { (I) First choice: } \\
\text { Ccfotaxime } 3-4 \times 2 \mathrm{~g} / \mathrm{d} \\
\text { Imipenem } 4 \times 500 \mathrm{mg} / \mathrm{d} \\
\text { Fluoroquinolone (e.g. Ciprofloxacin } 2 \times 500-750 \mathrm{mg} / \mathrm{d} \text { ) } \\
\text { (II) Alternatives: } \\
\text { Ampicillin, Gentamicin, free or fixed combination of } \\
\text { beta-lactam/beta-lactamase inhibitor (e.g. combinations } \\
\text { with Combactam or as Ampicillin/Sulbactam, } \\
\text { Piperacillin/Tazobactam, Ticarcillin/Clavulanate) }\end{array}$ & \\
\hline Serratia marcescens & $\begin{array}{l}\text { (I) First choice: } \\
\text { Cefotaxime } 3-4 \times 2 \mathrm{~g} / \mathrm{d} \\
\text { (II) Alternatives: } \\
\text { Fluoroquinolone (e.g. Ciprofloxacin) } \\
\text { Gentamicin. Imipenem }\end{array}$ & \multirow{2}{*}{$\begin{array}{l}\text { I) First choice: } \\
\text { Ceftazidim } 3 \times 2 \mathrm{~g} / \mathrm{d} \\
+ \text { Fluoroquinolone (e.g. Ciprofloxacin } 2 \times 500-750 \mathrm{mg} / \mathrm{d} \text { ) } \\
\text { (II) Alternatives: } \\
\text { Imipenem, Meropenem }\end{array}$} \\
\hline Pseudomonas aeruginosa & $\begin{array}{l}\text { (I) First choice: } \\
\text { Piperacillin } 4 \times 3 \mathrm{~g} / \mathrm{d} \\
\text { Imipenem } 4 \times 500 \mathrm{mg} / \mathrm{d} \\
\text { (II) Alternatives: } \\
\text { Fluoroquinolone (e.g. Ciprofloxacin) } \\
\text { Tobramycin, Amikacin }\end{array}$ & \\
\hline Anaerobe infection & $\begin{array}{l}\text { (I) First choice: } \\
\text { Clindamycin } 3 \times 600-900 \mathrm{mg} / \mathrm{d} \\
\text { Imipenem } 4 \times 500 \mathrm{mg} / \mathrm{d} \\
\text { Metronidazole } 3 \times 500 \mathrm{mg} / \mathrm{d} \\
\text { (II) Alternatives: } \\
\text { free or fixed combination of beta-lactam/beta-lactamase } \\
\text { inhibitor (e.g. combinations with Combactam or as } \\
\text { Ampicillin/Sulbactam, Piperacillin/Tazobactam, } \\
\text { Ticarcillin/Clavulanate) }\end{array}$ & $\begin{array}{l}\text { First choice: } \\
\text { Clindamycin } 3 \times 600-900 \mathrm{mg} / \mathrm{d} \\
\text { Piperacillin } / \text { Tazobactam } 3 \times 4 \mathrm{~g} / 0,5 \mathrm{~g} / \mathrm{d} \\
\text { Imipenem } 4 \times 500 \mathrm{mg} / \mathrm{d}\end{array}$ \\
\hline
\end{tabular}

(all given dosages are for healthy adults of $70 \mathrm{~kg}$ with normal liver and kidney function)

Table 4. Antibiotics for therapy of infectious arthritis

Lysostaphin is a $27 \mathrm{kDa}$ endopeptidase that was first isolated from a culture of Staphylococcus simulans by Schindler \& Schuhardt. The enzyme kills the organism by 
hydrolysing a pentaglycine cross-bridge structure unique to the staphylococcal cell wall. As the cell wall cross-bridges of S. aureus are composed of a high proportion of pentaglycine, both proliferating and quiescent S. aureus cells are highly sensitive to lysostaphin. Lysostaphin kills meticillin-susceptible S. aureus (MSSA) and MRSA equally well and has been demonstrated to be a potent therapeutic agent for $S$. aureus infections in various animal studies. In the USA, two therapeutic products formulated with recombinant lysostaphin for topical use have entered clinical studies. And recombinant lysostaphin is expected to be a potential alternative therapy for S. aureus infection[78].

For an overview of common substances and therapeutic regimes, see Table 4.

In patients undergoing débridement with retention of the prosthesis, 3-month courses of treatment for infection associated with hip prostheses and 6-month courses for infection associated with knee prostheses are often used. Oral therapy can be used if the agent has good oral bioavailability (e.g., quinolones, rimethoprim- sulfamethoxazole, and tetracyclines). In patients undergoing a two-stage exchange, systemic antimicrobial therapy is often administered for 4 to 6 weeks. Commercially available, preblended, polymethylmethacrylate impregnated with an antimicrobial agent is indicated for use in the second stage of a two-stage revision after elimination of active infection. Although it is not standard clinical practice, two studies involving a long period between the initial and second stages suggest that when a polymethylmethacrylate spacer impregnated with one or more antimicrobial agents or impregnated beads are used, the administration of systemic antimicrobial therapy for 2 weeks may be sufficient or systemic therapy may even be unnecessary[75,76].

\subsection{Prophylaxis}

In addition to good aseptic technique and procedures in the operating room, the administration of intravenous antimicrobial agents immediately before surgery minimizes the risk of infection. Cefazolin at a dose of $1 \mathrm{~g}(2 \mathrm{~g}$ if the patient weighs $\geq 80 \mathrm{~kg}$ ) every 8 hours or cefuroxime at a dose of $1.5 \mathrm{~g}$, followed by $750 \mathrm{mg}$ every 8 hours is recommended routinely; vancomycin at a dose of $15 \mathrm{mg}$ per kilogram every 12 hours (assuming normal renal function) is used in patients with a $\beta$-lactam allergy or MRSA colonization. Prophylaxis should begin within 60 minutes before surgical incision (within 120 minutes if vancomycin is used) and should be completed within 24 hours after the end of surgery. The entire antimicrobial dose should be infused before inflation of a tourniquet[77].

\section{References}

[1] National Hospital Discharge Survey: survey results and products. Atlanta: Centers for Disease Control and Prevention; 2009 [Accessed July 24, 2009].

http://www.cdc.gov/nchs/nhds/nhds_products.htm

[2] Lee K. Goodman S.B. Current state and future of joint replacements in the hip and knee. Expert Rev. Med. Devices 2008;5:383-393. [PubMed: 18452388]

[3] Goldenberg D.L. Septic arthritis. Lancet 1998;351:197-202. [PubMed: 9449882]

[4] Nade S. Septic arthritis. Best. Pract. Res. Clin. Rheumatol. 2003;17:183-200. [PubMed: 12787520]

[5] Stott N.S. Paediatric bone and joint infection. J. Orthop. Surg. (Hong Kong) 2001;9:83-90. [PubMed: 12468850] 
[6] Levine M. Siegel L.B. A swollen joint: why all the fuss? Am. J. Ther. 2003;10:219-224. [PubMed: 12756429]

[7] Lew D.P. Waldvogel F.A. Osteomyelitis. Lancet 2004;364:369-379. [PubMed: 15276398]

[8] Weichert S. Sharland M. Clarke N.M. Faust S.N. Acute haematogenous osteomyelitis in children: is there any evidence for how long we should treat? Curr. Opin. Infect. Dis. 2008;21:258-262. [PubMed: 18448970]

[9] Blyth M.J. Kincaid R. Craigen M.A. Bennet G.C. The changing epidemiology of acute and subacute haematogenous osteomyelitis in children. J. Bone Joint Surg. Br. 2001;83:99-102. [PubMed: 11245548]

[10] Lazzarini L. Mader J.T. Calhoun J.H. Osteomyelitis in long bones. J. Bone Joint Surg. Am. 2004;86-A: 2305-2318. [PubMed: 15466746]

[11] Gillespie W.J. Epidemiology in bone and joint infection. Infect. Dis. Clin. North Am. 1990;4:361-376. [PubMed: 2212594]

[12] Jämsen E, Huhtala H, Puolakka T, Moilanen T. Risk factors for infection after knee arthroplasty: a register-based analysis of 43,149 cases. J Bone Joint Surg Am 2009;91:38-47.

[13] Peersman G, Laskin R, Davis J, Peterson M. Infection in total knee replacement: a retrospective review of 6489 total knee replacements. Clin Orthop Relat Res 2001;392:15-23. [PubMed: 11716377]

[14] Pulido L, Ghanem E, Joshi A, Purtill JJ, Parvizi J. Periprosthetic joint infection: the incidence, timing, and predisposing factors. Clin Orthop Relat Res 2008;466:1710-5. [PubMed: 18421542]

[15] Choong PF, Dowsey MM, Carr D, Daffy J, Stanley P. Risk factors associated with acute hip prosthetic joint infections and outcome of treatment with a rifampin-based regimen. Acta Orthop 2007;78:755- 65. [PubMed: 18236181]

[16] Phillips JE, Crane TP, Noy M, Elliott TS, Grimer RJ. The incidence of deep prosthetic infections in a specialist orthopaedic hospital: a 15-year prospective survey. J Bone Joint Surg Br 2006;88:943-8. [PubMed: 16799001]

[17] Kurtz SM, Lau E, Schmier J, Ong KL, Zhao K, Parvizi J. Infection burden for hip and knee arthroplasty in the United States. J Arthroplasty 2008;23:984-91. [PubMed: 18534466]

[18] Murdoch DR, Roberts SA, Fowler VG Jr, et al. Infection of orthopedic prostheses after Staphylococcus aureus bacteremia. Clin Infect Dis 2001;32:647-9. [PubMed: 11181131]

[19] Berbari EF, Hanssen AD, Duffy MC, et al. Risk factors for prosthetic joint infection: case-control study. Clin Infect Dis 1998;27:1247-54. [PubMed: 9827278]

[20] Bongartz T, Halligan CS, Osmon DR, et al. Incidence and risk factors of prosthetic joint infection after total hip or knee replacement in patients with rheumatoid arthritis. Arthritis Rheum 2008;59:1713-20. [PubMed: 19035425]

[21] Dowsey MM, Choong PF. Obesity is a major risk factor for prosthetic infection after primary hip arthroplasty. Clin Orthop Relat Res 2008;466:153-8. [PubMed: 18196388]

[22] Kaandorp CJ, Krijnen P, Moens HJ, Habbema JD, van Schaardenburg D. The outcome of bacterial arthritis: a prospective community-based study. Arthritis Rheum. 1997; 40:884-92. 
[23] Kaandorp CJ, van Schaardenburg D, Krijnen P, Habbema JD, van de Laar MA. Risk factors for septic arthritis in patients with joint disease. A prospective study. Arthritis Rheum. 1995; 38:1819-25.

[24] Shirtliff ME, Mader JT. Acute septic arthritis. Clin Microbiol Rev. 2002; 15: 527-44.

[25] Udo Geipel. Pathogenic organisms in hip joint infections. International Journal of Medical Sciences 2009; 6(5):234-240.

[26] Jose L. Del Pozo, M.D., Ph.D. and Robin Patel, M.D. Infection Associated with Prosthetic Joints. N Engl J Med. 2009 August 20; 361(8): 787-794.

[27] Bennet G.C. Bennet S.J. Infection of bone and joint. Surgery (Oxford) 2006;24:211-214.

[28] Ciampolini J. Harding K.G. Pathophysiology of chronic bacterial osteomyelitis. Why do antibiotics fail so often? Postgrad. Med. J. 2000;76:479-483. [PubMed: 10908375]

[29] Trampuz A, Piper KE, Jacobson MJ, et al. Sonication of removed hip and knee prostheses for diagnosis of infection. N Engl J Med 2007;357:654-63. [PubMed: 17699815]

[30] Marculescu CE, Berbari EF, Cockerill FR III, Osmon DR. Fungi, mycobacteria, zoonotic and other organisms in prosthetic joint infection. Clin Orthop Relat Res 2006;451:64-72. [PubMed: 16906078]

[31] Unusual aerobic and anaerobic bacteria associated with prosthetic joint infections. Clin Orthop Relat Res 2006;451:55-63. Idem. [PubMed: 16906072]

[32] Berbari EF, Osmon DR, Duffy MC, et al. Outcome of prosthetic joint infection in patients with rheumatoid arthritis: the impact of medical and surgical therapy in 200 episodes. Clin Infect Dis 2006;42:216-23. [PubMed: 16355332]

[33] Piper KE, Jacobson MJ, Cofield RH, et al. Microbiologic diagnosis of prosthetic shoulder infection by use of implant sonication. J Clin Microbiol 2009;47:1878-84. [PubMed: 19261785]

[34] Marculescu CE, Cantey JR. Polymicrobial prosthetic joint infections: risk factors and outcome. Clin Orthop Relat Res 2008;466:1397-404. [PubMed: 18421538]

[35] Berbari EF, Marculescu C, Sia I, et al. Culture-negative prosthetic joint infection. Clin Infect Dis 2007;45:1113-9. [PubMed: 17918072]

[36] Peacock S.J. Moore C.E. Justice A. Kantzanou M. Story L. Mackie K. O'Neill G. Day N.P. Virulent combinations of adhesin and toxin genes in natural populations of Staphylococcus aureus. Infect. Immun. 2002;70:4987-4996. [PubMed: 12183545]

[37] Arciola C.R. Campoccia D. Gamberini S. Baldassarri L. Montanaro L. Prevalence of cna, fnbA and fnbB adhesin genes among Staphylococcus aureus isolates from orthopedic infections associated to different types of implant. FEMS Microbiol. Lett. 2005;246:81-86. [PubMed: 15869965]

[38] Peacock S.J. Day N.P. Thomas M.G. Berendt A.R. Foster T.J. Clinical isolates of Staphylococcus aureus exhibit diversity in fnb genes and adhesion to human fibronectin. J. Infect. 2000;41:23-31. [PubMed: 10942636]

[39] Bocchini C.E. Hulten K.G. Mason E.O. Gonzalez B.E. Hammerman W.A. Kaplan S.L. Panton-Valentine leukocidin genes are associated with enhanced inflammatory response and local disease in acute hematogenous Staphylococcus aureus osteomyelitis in children. Pediatrics 2006;117:433-440. [PubMed: 16452363]

[40] Sdougkos G. Chini V. Papanastasiou D.A. Christodoulou G. Tagaris G. Dimitracopoulos G. Spiliopoulou I. Methicillin-resistant Staphylococcus aureus 
producing Panton-Valentine leukocidin as a cause of acute osteomyelitis in children. Clin. Microbiol. Infect. 2007;13:651-654. [PubMed: 17371535]

[41] Cassat J.E. Dunman P.M. McAleese F. Murphy E. Projan S.J. Smeltzer M.S. Comparative genomics of Staphylococcus aureus musculoskeletal isolates. J. Bacteriol. 2005;187:576-592. [PubMed: 15629929]

[42] van de Lest C.H. Vaandrager A.B. Mechanism of cell-mediated mineralization. Curr. Opin. Orthop. 2007;18:434-443.

[43] Henriksen K. Neutzsky-Wulff A.V. Bonewald L.F. Karsdal M.A. Local communication on and within bone controls bone remodeling. Bone 2009;44:1026-1033. [PubMed: 19345750]

[44] Matsuo K. Irie N. Osteoclast-osteoblast communication. Arch. Biochem. Biophys. 2008;473:201-209. [PubMed: 18406338]

[45] Vaananen H.K. Laitala-Leinonen T. Osteoclast lineage and function. Arch. Biochem. Biophys. 2008;473:132-138. [PubMed: 18424258]

[46] Everts V. Korper W. Hoeben K.A. Jansen I.D. Bromme D. Cleutjens K.B. Heeneman S. Peters C. Reinheckel T. Saftig P. Beertsen W. Osteoclastic bone degradation and the role of different cysteine proteinases and matrix metalloproteinases: differences between calvaria and long bone. J. Bone Miner. Res. 2006;21:1399-1408. [PubMed: 16939398]

[47] Boyce B.F. Xing L. Functions of RANKL/RANK/OPG in bone modeling and remodeling. Arch. Biochem. Biophys. 2008;473:139-146. [PubMed: 18395508]

[48] Hikita A. Yana I. Wakeyama H. Nakamura M. Kadono Y. Oshima Y. Nakamura K. Seiki M. Tanaka S. Negative regulation of osteoclastogenesis by ectodomain shedding of receptor activator of NfkappaB ligand. J. Biol. Chem. 2006;281:36846-36855. [PubMed: 17018528]

[49] Tsezou A. Poultsides L. Kostopoulou F. Zintzaras E. Satra M. Kitsiou-Tzeli S. Malizos K.N. Influence of interleukin 1alpha (IL-1alpha), IL-4, and IL-6 polymorphisms on genetic susceptibility to chronic osteomyelitis. Clin. Vaccine Immunol. 2008;15:1888-1890. [PubMed: 18971305]

[50] Jochen Schulze.Thomas Bickert.F. Timo Beil.et al. Interleukin-33 is Expressed in Differentiated Osteoblasts and Blocks Osteoclast Formation from Bone Marrow Precursor Cells. Journal of Bone and Mineral Research.

[51] Garcia-Alvarez F. Navarro-Zorraquino M. Castro A. Grasa J.M. Pastor C. Monzon M. Martinez A. Garcia-Alvarez I. Castillo J. Lozano R. Effect of age on cytokine response in an experimental model of osteomyelitis. Biogerontology 2009;10:649658. [PubMed: 19123052]

[52] Lacey D.C. Simmons P.J. Graves S.E. Hamilton J.A. Proinflammatory cytokines inhibit osteogenic differentiation from stem cells: implications for bone repair during inflammation. Osteoarthritis Cartilage 2008;17:735-742. [PubMed: 19136283]

[53] Lau Y.S. Wang W. Sabokbar A. Simpson H. Nair S. Henderson B. Berendt A. Athanasou N.A. Staphylococcus aureus capsular material promotes osteoclast formation. Injury 2006;37(Suppl. 2):S41-S48. [PubMed: 16651071]

[54] Creagh E.M. O'Neill L.A. TLRs, NLRs and RLRs: a trinity of pathogen sensors that cooperate in innate immunity. Trends Immunol. 2006;27:352-357. [PubMed: 16807108] 
[55] Kahlenberg J.M. Lundberg K.C. Kertesy S.B. Qu Y. Dubyak G.R. Potentiation of caspase- 1 activation by the $\mathrm{P} 2 \times 7$ receptor is dependent on TLR signals and requires NF-kappaB-driven protein synthesis. J. Immunol. 2005;175:7611-7622. [PubMed: 16301671]

[56] Ting J.P.Y. Willingham S.B. Bergstralh D.T. NLRs at the intersection of cell death and immunity. Nat. Rev. Immunol. 2008;8:372-379. [PubMed: 18362948]

[57] Arend W.P. Palmer G. Gabay C. IL-1, IL-18, and IL-33 families of cytokines. Immunol. Rev. 2008;223:20-38. [PubMed: 18613828]

[58] Dinarello C.A. Immunological and inflammatory functions of the interleukin-1 family. Annu. Rev. Immunol. 2009;27:519-550. [PubMed: 19302047]

[59] Garzoni C. Kelley W.L. Staphylococcus aureus: new evidence for intracellular persistence. Trends Microbiol. 2009;17:59-65. [PubMed: 19208480]

[60] Stoodley P. Nistico L. Johnson S. Lasko L.A. Baratz M. Gahlot V. Ehrlich G.D. Kathju S. Direct demonstration of viable Staphylococcus aureus biofilms in an infected total joint arthroplasty. A case report. J. Bone Joint Surg. Am. 2008;90:1751-1758. [PubMed: 18676908]

[61] Khalil H. Williams R.J. Stenbeck G. Henderson B. Meghji S. Nair S.P. Invasion of bone cells by Staphylococcus epidermidis. Microbes Infect. 2007;9:460-465. [PubMed: 17331787]

[62] Mitchell G. Lamontagne C.A. Brouillette E. Grondin G. Talbot B.G. Grandbois M. Malouin F. Staphylococcus aureus SigB activity promotes a strong fibronectinbacterium interaction which may sustain host tissue colonization by small-colony variants isolated from cystic fibrosis patients. Mol. Microbiol. 2008;70:1540-1555. [PubMed: 19007412]

[63] Mahalingam D. Szegezdi E. Keane M. Jong S. Samali A. TRAIL receptor signalling and modulation: Are we on the right TRAIL? Cancer Treat. Rev. 2009;35:280-288. [PubMed: 19117685]

[64] Reott M.A. Ritchie-Miller S.L. Anguita J. Hudson M.C. TRAIL expression is induced in both osteoblasts containing intracellular Staphylococcus aureus and uninfected osteoblasts in infected cultures. FEMS Microbiol. Lett. 2008;278:185-192. [PubMed: 18070069]

[65] von Eiff C. Peters G. Becker K. The small colony variant (SCV) concept - the role of staphylococcal SCVs in persistent infections. Injury 2006;37(Suppl. 2):S26-S33. [PubMed: 16651068]

[66] Sendi P. Proctor R.A. Staphylococcus aureus as an intracellular pathogen: the role of small colony variants. Trends Microbiol. 2009;17:54-58. [PubMed: 19162480]

[67] von Eiff C. Staphylococcus aureus small colony variants: a challenge to microbiologists and clinicians. Int. J. Antimicrob. Agents 2008;31:507-510. [PubMed: 18180148]

[68] Fink B, Makowiak C, Fuerst M, Berger I, Schäfer P, Frommelt L. The value of synovial biopsy, joint aspiration and C-reactive protein in the diagnosis of late periprosthetic infection of total knee replacements. J Bone Joint Surg Br 2008;90:874-8. [PubMed: 18591595]

[69] Greidanus NV, Masri BA, Garbuz DS, et al. Use of erythrocyte sedimentation rate and C-reactive protein level to diagnose infection before revision total knee arthroplasty: a prospective evaluation.J Bone Joint Surg Am 2007;89:1409-16. [PubMed: 17606776] 
[70] Müller M, Morawietz L, Hasart O, Strube P, Perka C, Tohtz S. Diagnosis of periprosthetic infection following total hip arthroplasty - evaluation of the diagnostic values of pre- and intraoperative parameters and the associated strategy to preoperatively select patients with a high probability of joint infection. J Orthop Surg 2008;3:31.

[71] Love C, Marwin SE, Palestro CJ. Nuclear medicine and the infected joint replacement. Semin Nucl Med 2009;39:66-78. [PubMed: 19038601]

[72] Kwee TC, Kwee RM, Alavi A. FDG-PET for diagnosing prosthetic joint infection: systematic review and metaanalysis. Eur J Nucl Med Mol Imaging 2008;35:2122-32. [PubMed: 18704405]

[73] Schinsky MF, Della Valle CJ, Sporer SM, Paprosky WG. Perioperative testing for joint infection in patients undergoing revision total hip arthroplasty. J Bone Joint Surg Am 2008;90:1869-75. [PubMed: 18762646]

[74] Cabrita H, Croci A, De Camargo O, De Lima A. Prospective study of the treatment of infected hip arthroplasties with or without the use of an antibiotic-loaded spacer. Clinics (Sao Paulo) 2007;62:99- 108. [PubMed: 17505692]

[75] Whittaker JP, Warren RE, Jones RS, Gregson PA. Is prolonged systemic antibiotic treatment essential in two-stage revision hip replacement for chronic Gram-positive infection? J Bone Joint Surg Br 2009;91:44-51. [Erratum, J Bone Joint Surg Br 2009;91:700.]. [PubMed: 19092003]

[76] Stockley I, Mockford BJ, Hoad-Red-dick A, Norman P. The use of two-stage exchange arthroplasty with depot antibiotics in the absence of long-term antibiotic therapy in infected total hip replacement. J Bone Joint Surg Br 2008;90:145-8. [PubMed: 18256078]

[77] Bratzler DW, Houck PM. Antimicrobial prophylaxis for surgery: an advisory statement from the National Surgical Infection Prevention Project. Am J Surg 2005;189:395404. [PubMed: 15820449]

[78] Xin-Yi Yang. Cong-Ran Li. Ren-Hui Lou. et al. In vitro activity of recombinant lysostaphin against Staphylococcus aureus isolates from hospitals in Beijing, China. Journal of Medical Microbiology (2007), 56, 71-76. 


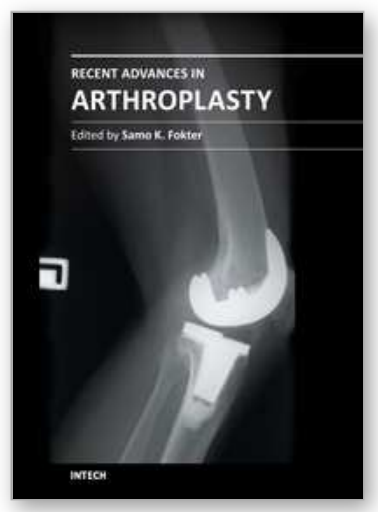

\author{
Recent Advances in Arthroplasty \\ Edited by Dr. Samo Fokter
}

ISBN 978-953-307-990-5

Hard cover, 614 pages

Publisher InTech

Published online 27, January, 2012

Published in print edition January, 2012

The purpose of this book was to offer an overview of recent insights into the current state of arthroplasty. The tremendous long term success of Sir Charnley's total hip arthroplasty has encouraged many researchers to treat pain, improve function and create solutions for higher quality of life. Indeed and as described in a special chapter of this book, arthroplasty is an emerging field in the joints of upper extremity and spine. However, there are inborn complications in any foreign design brought to the human body. First, in the chapter on infections we endeavor to provide a comprehensive, up-to-date analysis and description of the management of this difficult problem. Second, the immune system is faced with a strange material coming in huge amounts of micro-particles from the tribology code. Therefore, great attention to the problem of aseptic loosening has been addressed in special chapters on loosening and on materials currently available for arthroplasty.

\title{
How to reference
}

In order to correctly reference this scholarly work, feel free to copy and paste the following:

Weisheng Ye, Wei Shang and Yaqiong Yang (2012). Staphylococcus Infection Associated with Arthroplasty, Recent Advances in Arthroplasty, Dr. Samo Fokter (Ed.), ISBN: 978-953-307-990-5, InTech, Available from: http://www.intechopen.com/books/recent-advances-in-arthroplasty/staphylococcus-infection-associated-witharthroplasty

\section{INTECH}

open science | open minds

\author{
InTech Europe \\ University Campus STeP Ri \\ Slavka Krautzeka 83/A \\ 51000 Rijeka, Croatia \\ Phone: +385 (51) 770447 \\ Fax: +385 (51) 686166 \\ www.intechopen.com
}

\author{
InTech China \\ Unit 405, Office Block, Hotel Equatorial Shanghai \\ No.65, Yan An Road (West), Shanghai, 200040, China \\ 中国上海市延安西路65号上海国际贵都大饭店办公楼 405 单元 \\ Phone: +86-21-62489820 \\ Fax: +86-21-62489821
}


(C) 2012 The Author(s). Licensee IntechOpen. This is an open access article distributed under the terms of the Creative Commons Attribution 3.0 License, which permits unrestricted use, distribution, and reproduction in any medium, provided the original work is properly cited. 